\title{
Racism and media, in a moment of crisis and opportunity
}

\section{Gavan Titley}

To cite this article: Gavan Titley (2020) Racism and media, in a moment of crisis and opportunity, Ethnic and Racial Studies, 43:13, 2386-2394, DOI: 10.1080/01419870.2020.1789189

To link to this article: https://doi.org/10.1080/01419870.2020.1789189

册 Published online: 19 Aug 2020.

Submit your article to this journal

Шll Article views: 2343

Q View related articles $\sqsubset$

View Crossmark data $₫$ 


\title{
Racism and media, in a moment of crisis and opportunity
}

\author{
Gavan Titley \\ Department of Media Studies, Maynooth University, Kildare, Ireland
}

\begin{abstract}
This article provides the author's reply to the four book responses by Dreher, Georgiou, James and Saha. The discussion focuses on how their analytical engagement with the book's treatment of the ambivalences of digital media culture raise pertinent questions for focusing on anti-racism in media work and practices. It does so while reflecting on the extraordinary conditions of antiracist protest and revolt during which it was written in June 2020.
\end{abstract}

ARTICLE HISTORY Received 11 June 2020; Accepted 16 June 2020

KEYWORDS Racism; digital media; popular culture; postracialism; representation; migration

My book departs from a set of assumptions about the historicity of racisms and the multiplicity of media. I wondered, after its publication, if I had nonetheless saddled it with a misleadingly expansive title, the kind that aspires to stake out what is taken to be a given field, and propose a sweeping survey of it. Among the many admirable aspects of the generous and insightful engagements by Myria Georgiou, Malcolm James, Anamik Saha and Tanja Dreher is the extent to which they write not just to the book's keywords, but to the active importance of the title's conjunction. The focus of the analysis is not just racism in the media, but a more generative relation between racism and media. This conjoining has two dimensions. The first is an interdisciplinary concern with the lack of a sustained encounter between media theory and, broadly speaking, ethnic and racial studies. This is not to say, of course, that the study of race is absent from media and communication studies, but rather that it routinely circumscribed through thematic inclusion, a marginal or additional issue to be addressed rather than a consistent analytical dimension (for discussion of a recent critical venture addressing this, \#CommunicationSoWhite, see Ng, Costley White, and Saha 2020). Similarly, media concerns are prevalent in ethnic and racial studies, but media predominantly feature as an ideological source, structural factor or discursive illustration, not so much as a productive agent. (It is worth noting here that current work on the 
racial logics and effects of internet infrastructure and technological design marks the most sustained refusal of both of these limitations, see, most recently Benjamin 2019).

The second dimension is conjunctural: an attempt to explore the intersection of postracialism, as a discursive formation tending towards ahistorical and political closure on the meaning of racism, with the digital media ecology, a communicative infrastructure which depends, systemically, on the open circulation of discourse. In their reflections the contributors hone in on specific themes and arguments while consistently returning to the implications of this conjunctural orientation. Some of these reflections are methodological; both Georgiou and Dreher respond to a tension I consistently flag but do not fully address, which is that fine-grained contextual analysis of media in societies is difficult to negotiate with adequate attention to the transnational significances of media circulation and exchange, a tension that also flirts with parochialism when the contexts in question are primarily western European. In that regard, Dreher's extended reflection on these dynamics in "settler colonial Australia just after the first anniversary of the Christchurch massacre" is particularly appreciated, pointing, as it does, to how these conditions minimally demand more and deeper collaborative research that is capable of tracing media flows, and their translations and translocations, relationally.

It is a marker of the commitment to dialogical engagement in these essays that I found myself returning to review my own arguments - I hadn't read the book for a while, after all - and noticing how they had been refined and improved through these exercises in critical iteration and extension. Georgiou takes my engagement with Silverstone's (2007) discussion of media and "boundary work" and links it to the idea of the "digital border" (Chouliaraki and Georgiou 2019); an assemblage which encompasses both the digitized surveillance and regulation of illegitimised mobilities, and the "symbolic border" of mediatized representations and narratives which provided resources for both the nationalist mobilization and "humanitarian securitization" intertwined in the responses to post-2015 crisis migration. James, in recognizing the methodological influence of Stuart Hall on the book's analytical approach, follows through on this commitment by deepening my exploration of the contradictions involved in the global circulation of the photo of Alan Kurdi's body lying on a beach near Bodrum in Turkey in 2015. In this supplementary reading, James considers the conditions under which such an image can become generative of "an alternative humanist assemblage" which while clearly contingent and ephemeral, nevertheless transgresses the dehumanizing distancing enacted by the "symbolic border".

While this argument chimes thematically with Georgiou, it also speaks to a central concern of both Dreher and Saha. They consider the contexts and conditions in which representations come to matter, to flow through and with forms of political agency and cultural potential despite the apparently 
disabling character of an expansive media space in which the sheer abundance of representation and "infoglut", as Mark Andrejevic has argued, hastens a general "decline in symbolic efficiency"; a politically unsettling sensibility that regards all narratives as interchangeable, all representations as constructed, and "..all conclusions the result of an arbitrary and premature closure of the debate" $(2013,11)$. A dominant normative response to these fragmented conditions has been to ignite one of those periodic exercises in longing for an unitary and unified public sphere, exercises which have been extensively critiqued for their constitutive inattention to race, gender and class. In contemporary public debate, fidelity to these mythic conditions encompasses techno-determinist anxiety about "echo chambers", and the unseemly degree of attention a transatlantic coterie of columnists dedicate to keeping students under surveillance, searching out scandalous evidence of the wilful separatism of "safe spaces" and the anti-democratic refusal to debate with white supremacists. In different ways, James' attention to how "not yet fully formed alternatives" emerge in popular culture; Dreher's reinstatement of the importance of Indigenous and community media to the "many and varied forms of media activism on the part of racialized communities"; and Saha's consideration of the current emergence of "often explicitly intersectional ... black and brown online platforms" suggests that what is needed is more meaningful and purposeful "fragmentation", not less.

This sensibility emerges because these extensive engagements read the book's conjunctural orientation in terms of its significance for antiracisms, those forms concerned, to use Georgiou's formulation, with media as an "integral element of systems of power and knowledge that matter to politics (through representation), institutions (through bordering), and to public culture (through recognition)". Indeed, the three other essays can be read as a complementary set of intensifications on this question. James's attention to "not yet fully formed alternatives" reminds us of the analytical and aesthetic reduction involved in attempting to designate cultural practices as "antiracist" or not, a category error that fails to pay attention to the contradictory ways in which they "offer textures amenable to anti-racist cultural projects". Dreher is interested in the ambiguous potentialities of those moments of intensive media concentration that command attention across these otherwise fragmented media terrains, in this instance in the aftermath of the Otautahi/Christchurch massacre. Here, as she notes, "for a brief moment in Australian media culture, space was held for First Nations voices on settler colonialism as a structure rather than an event". For Saha, a more enduring shift from event to structure requires moving from the temporality of media events to the materiality of media infrastructures and resources, a project turned towards addressing how "media can produce forms of solidarity, community and commonality" without reproducing the problem of locating transformative potential in the question of representation. 
There is much, in another draft of this response, that I thought to draw from this layered treatment of antiracist possibilities. As I wrote it, however, it became impossible to ignore the degree to which the tumult of 2020 unsettles anything written only mid-way through it. The global spread of Covid-19 was at its pitch of intensity in Europe when I received these essays. I submitted this response as the extraordinary mobilisations in the USA following the brutal police killing of George Floyd continued to gather pace, and as transnational solidarity and political particularization began to spread across contexts. Critical junctures of this kind place writing such as this in parenthesis; to ignore them in favour of purely textual engagement is to write out of time, to do much more than acknowledge the "known unknown" is to write against it. It is a basic truth, as Joshua Clover notes, that theory in these circumstances must proceed from humility (2020), but given the book's central preoccupation with the impact of prevailing communicative and political conditions on the "public discussion" of racism, it seems necessary to include some very tentative remarks.

The conjunctural intersection of postracialism and circuits of digital media produces, in Malcolm James' neatly summary of my argument, " ... conjecture and contestation as a presiding condition" of mediated public culture. What the book terms "debatability", consequently, takes shape through "... the constant contest as to what constitutes racism, as to whose "definition" and voice counts, and as to the consequences that should stem from these fractious forms of public recognition and denial" (Titley 2019, 3). As each of the contributors note, these dynamics inform grindingly familiar and repetitive patterns in public culture, regularly played out in highly familiar cultural forms - media spectacles of innocence and/or plain-speaking, where everything from blackface rituals to contrarian adventures in "race realism" generate intensive bursts of circulating discourse and affect, hinging on whether the statement or practice in question is categorically racist, or not.

The idea is not intended as a definitive concept, but rather as a way of marking out critical distance from the deliberative and democratic assurance associated with the idea of public debate. For all the general recognition of mediated communication's pervasive complexities, limitations and forms of symbolic violence, debate remains the central conceit employed to think about purposeful communication and the exchange of ideas in public culture (note the common North American trope of a "national conversation about race/racism"). By emphasizing the spectacular and ritualized dimensions of these events, debatability aims to draw attention to the ways in which racism is made the subject of particular forms of repetitive and scripted debate. These forms are a product of postracial closure on the historicity of racism, that is, the insistence that while it is widely agreed that racism is evil, its meaning is set and given because it is derived from its murderous and overtly hierarchical pasts; its acceptable sense is constrained, as Alana 
Lentin has recently argued, to " ... the predominance of individualist moralism; the reliance on an overly narrow, strictly biological and hierarchical account of racism; and the universalisation of racism as equally practiced by all groups independent of status and power" $(2018,411)$.

Antiracist movements and actions, of course, have never been dependent on agreed definitions of racism in public culture, and recognize that any "definition" of racism is necessarily political and a site of political contest. Nevertheless, public antiracism also involves identifying affinities and similarities in the experiences and histories of racialization inflicted on different populations through dispossession, exploitation, securitization, exclusion and conditional, coercive inclusion, and thus also forging interconnections with other traditions of liberatory thought and activism (Bhattacharyya, Virdee, and Winter 2020). If racism, as A. Sivanandan (1990) pithily put it, "never stays still", then this process of naming and articulation is often part of generating collective and mobilizing understandings. As Gopal (2019) argued recently,

Far from wallowing in victimhood, people who challenge racism are acting as responsible agents of change. At a time when the forces of violent racism are globally in the ascendant once again, we can help them along by refusing to name it as such. Alternatively, we can do the right thing; actively acknowledge racism's existence and try to rein in its power.

The problem is that when postracialism amounts to - concerted attempts at substantive control over the acceptable public definition of racism, this commitment to historicizing acknowledgement is easily cast as excessive, as "making everything about racism", and even as Georgiou notes, as a restriction on free speech and innocent cultural expression (I have subsequently written more specifically on this in terms of contemporary free speech politics, see Titley 2020). Dreher is spot on in noting how a pronounced feature of the debatability of racism is the "discursive game-playing of reversals and negations that has been a defining feature of racism since at least the 1970s". The raft of "contrarians" in Anglophone media that depend on the accelerated dynamics of the "attention economy" to continually recycle this discursive heritage as nothing more than propositions for reasonable debate are certainly evidence of this. What the conceptual discussion pays equal attention to is that this insistence on closure as to the meaning of racism is mediated by the digital media ecology's structural openness, and its dependence on "debate" as a modality for the incessant invitation to and circulation of discourse, to generate content, comment and reaction.

Debatability is the product of this intersection, a condition that those who experience racism must endure and negotiate to attempt to speak about racism in public, shaped by the assumption that because nearly everybody agrees that racism is morally bad, "everybody" can equally debate whether 
something is racist or not, and debate it within media circuits that depend on the constant circulation of opinion and reaction in pursuit of the scarce resource of attention. This is more than (white) confusion as to what racism means, it is an argument about how the denial of racism can occur not just through silencing, but through noise, not just through a lack of attention to racism, but through an excess of particular kinds of attention. Writing in the aftermath of the "Laurence Fox affair" that Saha discusses, the journalist Kuba Shand-Baptiste (2020) was clear that the proliferation of debates about whether or not there is "racism in Britain" was leading to a "deliberate exodus from our broadcast media of exactly the voices we need to hear more of". This debatability, therefore, this incessant recursive attention as to what counts as racism and who gets to define it, needs to be seen, I think, as a generative dimension of the politics of racism in irreducibly diverse societies dominantly imagined as both white and anti-racist.

Malcolm James, in agreeing that the "over-riding message" of the book is that "debatability" facilitates racism, is astute in tracing the generative importance of contradictions to these dynamics. This is most evident, perhaps, in the flows of meta-commentary on social media that, under particular, contingent conditions, cohere into moments of sustained unsettling of postracial presumption. The question posed by Dreher's discussion of the aftermath of the Islamophobic terror attack in New Zealand is whether such concerted disruption of the circuits of debatability is dependent on the media temporality of the event, where the event, more often than not, takes shape in the immediate aftermath of violent horror. This question is acutely posed now, if in a very different shape, by the extraordinary "festival of the oppressed" being sustained across North American cities, a revolt that, through its shape-shifting presences and occupations, as well as the rich visuality and resistant allusiveness of its real-time archives, links police brutality to systemic discrimination to socio-economic deprivation to the contours of racial capitalism. The wave of protest and rebellion has shattered the fictions necessary to what Davis (2007) termed the "muted racism" of neoliberal governance, linking them to the structures that maintain racialized inequalities and oppression, forging an event that reveals structure, to use Dreher's terms. Here, at this moment, postracial control over the accepted definition of racism is but one of the apparently resilient public mythologies being dismantled, for as Keeanga-Yamahtta Taylor (2020) suggests, the protests, inter alia, refuse the circuitries of biddable noise:

The question is: How do we change this country? It's not a new question; for African-Americans, it's a question as old as the nation itself. A large part of the reason that rebels swell the streets with clenched fists and expressive eyes is the refusal or inability of this society to engage that question in a satisfying way. Instead, those asking the question are patronized with sweet-sounding speeches, made with alliterative apologia, often interspersed with recitations 
about the meaning of America, and ultimately in defense of the status quo. There is a palpable poverty of intellect, a lack of imagination, and a banality of ideas pervading mainstream politics today. Old and failed propositions are recycled, but proclaimed as new, reviving cynicism and dismay.

At the time of writing, the situation remains fluid and complex, an ambiguity met with performative declarations of, predictably, both unprecedented rupture and inevitable co-option.

It is worth noting, however, that in terms of the dynamics of debatability, there is burgeoning evidence of a sustained refusal of African American and other journalists to submit this reality to the artificial bifurcations of "balance"/both sides now/view from nowhere frameworks, a practice of objectivity which is increasingly critiqued as a form of "white gaze", where describing racism, without the prophylactic of inverted commas, is perceived as too political (journalists at the Pittsburgh Post-Gazette, for example, went public with the management's decision to remove Black reporters from protest coverage for fear of "bias", Robinson 2020. For a longer discussion of the roots of this change in journalistic experiences of covering the Ferguson uprising in 2014; see Smith 2020). It is in the context of this kind of open refusal of the suppositions wired into entrenched professional norms that Saha's work on the need for "reparative justice" in how the "means of cultural production" are distributed and accessed by racialised minorities is critical, strategies that are "operationalised at the level of the political economic, rather than the level of representation" (see also Saha 2018).

In Europe, what is currently of note is the urgency and facility with which Black Lives Matter protests and actions have mobilized not only in solidarity with George Floyd and the US protests, but also to refuse the kind of European postracial exceptionalism that is so often in part reproduced by gesturing at the brutal, exteriorizing otherness of the US. The well-known Swedish politician Carl Bildt provided an exemplary illustration, tweeting on June 2 that

For all of its challenges and shortcomings, which we all spend time discussing, I think these days it's more obvious than ever that Europe is the most decent place in the world to live and to prosper in at this time in our history.

During these same days, protests and events subjected this exceptionalism to a kind of rolling immanent critique, drawing on the sudden willingness of governments, institutions and corporations to express their abhorrence of racism to name and link those practices and structures hegemonically disqualified from being understood and opposed as racist: the epidemic of police violence in France, with the slaying of Floyd explicitly linked to resurgent demands for justice for Adama Traoré and other victims of police killing; the treatment of refugees at Europe's militarized borders, whose 
exclusion and invisibilised immiseration is seen as the undeclared conditionality of the prosperity and peace referenced by Bildt; the dehumanisations of Black Face, where the aggressively curated "white innocence" (Wekker 2016) of Zwarte Piet in the Netherlands can no longer, it seems, resist the force of transatlantic reflexivity; the punitive structures of the direct provision system, which can not hide behind Ireland's particularistic mode of innocence, the non-racist alibi of postcolonial sentimentality. Vignettes and snapshots of the moment, yes, but ones which nonetheless show ways through and out of the dynamics of debatability, the noise that says that racism is everywhere and nowhere, simultaneously.

\section{Disclosure statement}

No potential conflict of interest was reported by the author(s).

\section{References}

Andrejevic, M. 2013. Infoglut: How Too Much Information Is Changing the Way We Think and Know. New York and London: Routledge.

Benjamin, R. 2019. Race After Technology: Abolitionist Tools for the New Jim Crow. Cambridge: Polity.

Bhattacharyya, G., S. Virdee, and A. Winter. 2020. "Revisiting Histories of Anti-Racist Thought and Activism." Identities: Global Studies in Culture and Power 27 (1): 1-19.

Chouliaraki, L., and M. Georgiou. 2019. "Borders." In The Sage Handbook of Media and Migration, edited by K. Smets, K. Leurs, M. Georgiou, S. Witteborn, and R. Gajjala, 25-33. London: Sage Publications.

Davis, D.-A. 2007. "Narrating the Mute: Racializing and Racism in a neo- Liberal Moment." Souls: A Critical Journal of Black Politics, Culture and Society 9 (4): 346-360.

Gopal, P. 2019. "Id we can't Call Racism by its Name, Diversity will Remain a Meaningless Buzzword." The Guardian, October 8. Accessed 5 June 2020. https:// www.theguardian.com/commentisfree/2019/oct/08/racism-diversity-nagamunchetty-bbc-inflammatory-language.

Lentin, A. 2018. "Beyond Denial: 'not Racism' as Racist Violence." Continuum: Journal of Media \& Cultural Studies 32 (4): 400-414.

Ng, E., K. Costley White, and A. Saha. 2020. "\#CommunicationSoWhite: Race and Power in the Academy and Beyond." Communication, Culture \& Critique 00 (2020): 1-9.

Robinson, I. 2020. "Pittsburgh Post-Gazette Bars Black Reporters, Citing 'bias'." The Root, June 7. https://www.theroot.com/pittsburgh-post-gazette-bars-black-reportersfrom-cover-1843944509.

Saha, Anamik. 2018. Race and the Cultural Industries. Cambridge: Polity.

Shand-Baptiste, K. 2020. "We don't Need More of the Same Bigoted Debate." $e$ Independent, January 29. Accessed 30 January 2020. https://www.independent.co. uk/voices/racism-bbc-question-time-today-times-radio-lbc-broadcast-a9308396. html.

Silverstone, R. 2007. Media and Morality: On the Rise of the Mediapolis. Cambridge: Polity.

Sivanandan, A. 1990. Communities of Resistance: Writing on Black Struggles for Socialism. London: Verso. 
Smith, B. 2020. "Inside the Revolts Erupting in America's Big Newsrooms." The New York Times, June 7. https://www.nytimes.com/2020/06/07/business/media/new-yorktimes-washington-post-protests.html?fbclid= IwAR01yQnaByHOjLVe9pIBoStlv96Qv_NunPCWIOKruC0MxkWSMU2ezHUwzY4.

Taylor, K.-Y. 2020. "How do we Change America?" The New Yorker, June 8. https://www. newyorker.com/news/our-columnists/how-do-we-change-america.

Titley, G. 2019. Racism and Media. London: SAGE Publications Limited.

Titley, G. 2020. Is Free Speech Racist? Cambridge: Polity.

Wekker, G. 2016. White Innocence: Paradoxes of Colonialism and Race. Durham: Duke University Press. 